\title{
Pedagogical Approaches for an Effective Classroom Management
}

\author{
Narayan Prasad Adhikari \\ adhikari_np@yahoo.com \\ Lecturer \\ Central Department of Education, TU, Kirtipur
}

\begin{abstract}
This study aimed to find out the pedagogical approaches for effective classroom management. The study is also undertaken to explore the teacher's opinions on effective classroom management. The study has addressed the research question "how teachers can effectively manage a classroom with a wide range of learning abilities and styles, in a student-centered way". It is adopted the qualitative research design. Qualitative data were taken from in-depth interviews. Thematic analysis and verbatim analysis have been done. Data were analyzed on the themes of student-centered classroom management, reactive and proactive classroom management strategies, cooperative discipline, culturally responsive teaching teacher's role, and classroom management. The study's findings entail that a well-managed classroom is a powerful motivator for students' learning. Reactive and proactive classroom, cooperative and collaborative learning atmosphere, culturally responsive teaching and learner-friendly teaching by the teacher, has been identified as the pedagogical approaches for effective classroom management. Based upon the findings, it can be suggested that the school principals should constantly organize seminars and workshops for teachers to get them aware of effective classroommanagement techniques. The study further implies a constant need to introduce and use new-classroom-management behaviors from the side of teachers.
\end{abstract}

Keywords: Classroom management, pedagogical approach, strategies, culturally responsive teaching, learning environment.

\section{Introduction}

Effective education has become a need of the day. It refers to the degree to which schools accomplish their educational objectives. Teachers play a crucial role in shaping effective education (Hattie, 2009). Effective teaching and learning cannot occur in poorly managed classrooms (Jones \& Jones, 2012). Effective classroom management strategies support and facilitate effective teaching and learning. It is generally based on establishing a positive classroom environment encompassing effective teacher-student relationships. All educational plans involving teaching and learning take place in the classroom for effective instruction. 
According to Kyriacou (2004), the classroom is the meeting point for teachers and students where curricular activities are implemented. Educational objectives cannot be fully achieved without using a conductive classroom environment. The classroom is characterized by a network of interpersonal relationships directed at attaining educational goals. Oyira (2006) argues that interpersonal relationship is the reciprocal behavior that occurs between individuals, such as exchanging information, expression, and mutual activities. A good classroom environment must be well ventilated, fully supplied with chairs and desks, an adequate spatial arrangement, a sizeable chalkboard, good floors, beautiful walls, and lightings (Kolawole, 2004).

A good classroom environment facilitates desirable behavior and attitude among students, thus positively enhancing their academic performance. Such an environment provides an opportunity for effective teacher-students and student-students interaction. Teachers are responsible for guiding every student's holistic development and meaningful learning in their classroom (Save the Children, 2008).

Well classroom management is sought for effective instruction. Evertson \& Weinstein (2006) state classroom management as "teachers' actions to create an environment that support and facilitates both academic and social-emotional learning". This view concentrates on the teacher's responsibility and relates to the use of classroom management strategies to address multiple learning goals for the students. Students' academic achievement in a particular classroom can be attributed to the teachers' ability to manage and control the classroom during instruction. Oyira (2006) argues that the variable that measures the learning classroom-learning environment perceived by students actually predicts their attitude towards schooling and academic performance.

The effective classroom focuses on preventive rather than reactive classroom management procedures (Lewis \& Sugai, 1999). Teachers, however, also frequently use reactive strategies (e.g., punishing disruptive students; Shook, 2012), whereas it is unclear whether these strategies effectively change student behaviour. This may be caused by a lack of knowledge about the effectiveness of preventive strategies or by the lack of belief in their effectiveness (Peters, 2012). Teachers do not always believe in the effectiveness of particular strategies despite the sufficient empirical evidence that the strategy has been implemented successfully in many classrooms (Smar \& Brent, 2010).

However, daily practice in education has been changing rapidly. It is increasingly characterized by student-centered approaches to learning, with a large emphasis on students' meta-cognitive skills (Dignath, Buttner, \& Langfeldt, 2008) and cooperative learning (Kagan, 2005). Moreover, more and more technology has been used for effective classrooms, such as interactive whiteboards, tablets, and laptops (Schussler, Poole, Whitlock, \& Evertson, 2007). These changes most likely have had a significant impact on the demands placed on teachers' classroom management skills.

One of the most challenging functions of a teacher is classroom management and control. The teachers' effectiveness in teaching is assessed in terms of his ability to use varied classroom management techniques to control students towards effective and meaningful learning during 
instruction. Thus, it is very difficult to identify these effective teacher characteristics because personal traits are fixed in feelings and beliefs. We can never observe directly and not assess using simple questionnaires (Ostorga, 2003). Classroom management entails planning, supervising, controlling, and coordinating the pupils' activities of pupils in the teaching-learning process. According to French, Imms, and Mahat, (2020), successful classroom management enhances students questioning and exploration only if the learning environment is conducive. Thus, classroom behaviour management should be seen as integral to teachers' overall capacity to effectively teach and manage their classroom, enhanced with pedagogically sound techniques. Classroom management techniques used in this study refer to the strategies adopted by teachers to ensure good behavior in the classroom and thus create a healthy and conducive atmosphere for learning.

Though effective classroom management has become a prerequisite for effective instruction and learning achievement, much discussion upon the strategies to adopt for effective management has not been made so far in our context. To capitalize the teachers' knowledge base of the strategies, an explorative study is essential to conduct considering both the theoretical insights and practical activities. Considering this, the present research has focused on exploring the pedagogical strategies for effective classroom management. Most of the schools in Nepal do not have a child-friendly environment, and thus it seems necessary to have effective leadership in the schools.

\section{Insights from the Review}

The study by Marzano et al. (2003) is the most recent meta-analysis of effective classroom management; it used the number of disruptions in classrooms as the outcome variable and included student engagement and student achievement as outcome measures. This meta-analysis has been widely cited in the classroom management literature used in teacher training programs. The study by Oliver, Wehby \& Reschly (2011) reports on the effects of classroom management practices on problem-student behavior. The meta-analysis by Durlak, Weissberg, Dymnicki, Taylor \& Schellinger (2011) concentrates on the effectiveness of social and emotional learning programs on various student outcomes.

As specified in the study of Marzano et al., (2003), the four components of effective classroom management are rules and procedures, disciplinary interventions teacher-student relationships, and mental set. The authors state that, ineffectively managed classrooms, some clear rules and procedures express the expected behavior. Rules refer to general behaviors relevant to treating each other; procedures refer to behaviors in specific situations. These include strategies for punishing negative behavior and reward for positive behavior. The third component of effective classroom management includes techniques for teachers to establish appropriate levels of dominance and cooperation in the classroom to optimize teacher-student relationships.

A study by Johnson (1980) identified four key characteristics correlated with teacher effectiveness: having sound knowledge of the subject matter, taking a personal interest in each student; establishing a caring and warm atmosphere, and showing enthusiasm with students. Other studies have identified several characteristics of an effective teacher: confidence, effective 
communication, adaptability to change, being a lifelong learner, competence, accepting of others, patient, organized, hardworking, and caring (Malikow, 2006; Daniel, 2010). Kebritchi, Lipschuetz, and Santiague (2017) state that excellent teachers are those who can teach and at the same time create a learning environment within the class to the point that the students enjoy learning and love to learn under that teacher. Teachers are the pillars responsible for the success or failure of our educational system.

Witcher, Onwuegbuzie \& Minor (2001) suggested six themes for the characteristics of effective teachers. They include student-centeredness, enthusiasm for teaching, ethical values, classroom and behaviour management, teaching methodology and knowledge. On the other hand, Hattie (2003) presented a different perspective on the characteristics of an effective teacher as someone who knows their subject matter well. Also, he argued that identifying essential representations of their subject can guide and motivate learning through classroom activities, monitor learning and provide effective feedback, attend to attentive attributes, influence student outcomes, and manage an effective classroom.

Oliver et al. (2011) focuses on universal, whole-class classroom management procedures. The findings exposed that teachers' classroom management practices had a significant, positive effect on decreasing problem behavior in the classroom. Students were less disruptive and showed less inappropriate and aggressive behavior in the treatment classrooms compared with the control classrooms. Literature suggests that a good learning environment is important for a successful school.

\section{Research Questions}

This study envisaged the answer to the following research questions:

1. What pedagogical approaches can be found in the relevant literature for effective classroom management?

2. Which classroom management strategies and programs can effectively support and facilitate academic, behavioral, social-emotional, and motivational outcomes in education?

3. How does relevant literature suggest the theories for student-centered classroom management?

\section{Process and Methods}

A qualitative research design has been employed to conduct this study. Document analysis has been used to collect the data required for this study. According to Kothari (2004), research design means a plan, a blueprint, or a guide for data collection and interpretation. Within this particular qualitative approach, a descriptive method was deemed most beneficial. The constant process of exploring the theoretical insights and linking them up to the questions raised in the study has been used to triangulate data. Using multiple methods or data sources in research is called 'triangulation' which enables a greater understanding of complex human behavior and provides multiple perspectives (Denscombe, 1998). Thus, a descriptive design in the spirit of a qualitative approach has been used as the most appropriate course of action. 


\section{Results and Discussion}

After a thorough analysis of the available documents, the significant findings have been presented and summarized descriptively. This entire discussion has been made being consistent with the available literature, papers, articles, and journals:

\section{Perspectives on Classroom Management}

The findings of this study are related to the perspectives on classroom management, practice classroom management and proactive classroom management. In this regard, Evertson \& Weinstein (2006) perceive classroom management as the actions that teachers take to create a supportive environment for students' academic and social-emotional learning. They describe five types of activities. To attain a high-quality classroom management, teachers must i) develop caring, supportive relationships with organize with, among students ii) organize, and implement instruction in ways that optimize students' access to learning. Marzano et al. (2003) also express the importance of developing favorable teacher-student relationships.

Additionally, Everts on and Weinstein (2006) state that teachers should iii) encourage students' engagement in academic tasks, which can be done by using group management methods. Teachers must iv) promote the development of students' social skills and self-regulation. Finally, Evertson \& Weinstein (2006) state that teachers should v) use appropriate interventions to assist students with behaviour problems. Evertson and Weinstein (2006) proposed the last two actions indicate that effective classroom management improves students' behaviour and achievement.

Brophy (2006) presents a similar definition of the notion and said: "classroom management refers to actions taken to create and maintain a learning environment conducive to successful instruction". Both definitions emphasize the importance of actions taken by the teacher to facilitate learning among the students. Classroom management strategies refer to teachers' management of student behaviour to construct a classroom atmosphere that fosters the development of effective teaching and child learning (Brophy, 1988). Effective classroom management strategies have been shown to significantly influence student achievement, student attitudes towards schoolwork, student social competence, and student emotional and behavioural functioning (Lewis, Romi, Katz, \& Qui, 2008). Effective teachers also recognize that students have 'unique learning styles'(SadlerSmith, 1996). Mujis (2001) suggests that teaching strategies vary according to students' diverse learning needs. Teaching should also be interactive in that teachers should involve students by asking relevant questions and giving timely feedback. Teachers also need to have an active role in teaching and learning in the classroom. As research, I reflect that student needs different learning needs. School headteachers and stakeholders have to manage classrooms in students' learning environments to address this.

\section{Reactive Classroom Management Strategies}

The reactive strategy means the tricks or plan of actions to manage students' misbehaviour (Infantino \& Little, 2005). Using a behavioral observation schedule to study how teachers reacted to student behavior, Merrett \& Wheldall (1993) found that teachers often respond negatively, using high levels of punishment. This study is consistent with more recent research findings demonstrating that teachers use predominantly positive responses for academic behaviors and 
negative reactions for problematic social behaviors (Chaw, \& Tang, 2018). The rapid termination of student problem behavior is an essential consideration for teachers. It helps prevent the students' misbehaviors' potential disruptive effects on other children. Furthermore, most reactive strategies are typically quick and easy to administer (Maag, 2001).

Teachers are often reinforced for being reactive towards their students, and the students are often accidentally supported for classroom misbehaviour. This reinforcement catch is likely to lead to continued behavioural breakdowns in the classroom rather than improved child responding over time. Although reactive strategies may provide the teacher with a short-term solution to unwanted behavior, such procedures rarely produce long-term results because they fail to teach children a more prosaically alternative to problem responses (Hall \& Hall, 2003).

\section{Proactive Classroom Management Strategies}

According to Sanford, Emmer \& Clements (1983), proactive approaches to behavior management emphasize student involvement and co-operation in classroom activities and create a positive working environment. In this regard, Gettinger (1988) described three features that distinguish proactive strategies from other approaches. First, proactive strategies are by definition preventive in that the goal is to discourage the event of problem behaviours before they occur. Second, the teacher facilitates learning and manages the class by focusing primarily on the students' achievement and development of academic skills. Third, group components of classroom management are promoted instead of emphasizing individual student behaviour (Kern $\&$ Clemens, 2007). Thus, there appears to be a substantial gap between classroom intervention research and practice.

\section{Co-operative and Conducive Classroom Atmosphere}

Students need to be given responsibilities and held accountable for their actions. According to Charles (2005), Albert's believes all students need to feel capable while connecting with others and contributing in the classroom, school and community. Acharya, (2016) states, "Albert's main focus is on helping teachers meet students' needs, thereby prompting students to co-operate with the teacher and each other". When students are active participants in their learning and feel their contributions are valued in the classroom, they are more likely to positively affect school. One specific characteristic of cooperative discipline is ensuring students feel connected in the classroom (Charles, 2005). Students who feel comfortable in the school will be more willing to take risks and share unique ideas and opinions. Both the co-operative discipline management program encourages students to contribute their individual ideas and opinions to improve the classroom environment. Charles (2005) indicates that with co-operative discipline it is important to, "ask students to state their opinions and preferences about class requirements, routine and other matters". When students and teachers are working together to manage the classroom cooperatively, there is shared leadership and responsibility. This type of cooperative management will minimize disruptions and create a more productive learning environment.

\section{Culturally Responsive Teaching}

Another classroom management theory is culturally responsive teaching'. Teachers must develop the knowledge, skills, and predispositions to teach children from diverse racial, ethnic, language, and social class backgrounds because classrooms today are continuing to become increasingly 
diverse (Weinstein, Curran \&Tomlinson-Clarke, 2003). In order to be culturally responsive, we must acquire 'cultural content knowledge.' We must learn, for example, about our students' family backgrounds, their previous educational experiences, their cultural norms for interpersonal relationships, their parents' expectations for discipline, and the ways their culture treat time and space. Teachers can set the tone for their classroom on the first day with their welcome and continue to be role models for their students throughout the school year. The physical environment of a classroom reflects the teacher's respect for diversity. Albert's Cooperative Discipline includes similar management strategies as Culturally Responsive Teaching by stating that teachers need to communicate, "that it is all right for each student to be as he/she is, regardless of culture, abilities, disabilities, and personal style" (Charles, 2005). Teachers must remember to encourage a positive, culturally responsive learning environment because students of all cultural backgrounds need to feel comfortable in the classroom to maximize their learning opportunities.

Learning about students' families and working with families in and out of the classroom is essential, but can cause conflicts when the home and school cultures run over. Teachers need to be aware of the cultural differences and accommodate the student and family needs and gaining insight into cultural values and habits helps teachers monitor their reactions to student behaviors that they might deem bad, but that is considered normal or even valued in the students' home culture (Bondy \& Ross, 2008). Culturally responsive teaching requires constant communication, patience, and education from all teachers and students, but is a necessity in a student-centered classroom.

\section{Student and Teacher Relationships}

To build a classroom and school community, teachers must develop a positive bond of relationship with each student. In addition, teachers must encourage student-peer solid relationships. According to Dollard, Christensen \& Colucci (1996), "the positive connection formed within a relationship between student and teacher becomes the foundation for all interaction in the classroom". Students must feel safe and express their feelings in a classroom to excel academically. According to Bondy \& Ross (2008), "what is missing is not skill in lesson planning, but a teaching position that communicates both warmth and a non-negotiable demand for student effort and mutual respect". Teachers need to give up some control and trust their students to work and be teachers in student-centered classrooms. Students can learn a lot from each other and student-centered classrooms have valuable discussions throughout the day. Teachers need to facilitate, not control, conversations.

As stated above, classroom management strategies are tools that the teachers can use to help create such an environment, ranging from activities to improve teacher-student relationships to rules to regulate student behavior. Although it is generally assumed that preventive strategies are more effective than reactive strategies, reactive strategies are sometimes needed to reduce disruptive or undesired student behavior when preventive strategies do not work.

According to Save the Children (2008), some pedagogical approaches of effective classroom management are enlisted as: 


\section{Recognizing the fact that children learn differently}

Though teaching is generally a group activity, learning is very individual. Sometimes it is difficult for teachers to realize that all students learn differently. As teachers plan for their teaching-learning activities, they must keep this in mind. Effective teachers are sensitive to such differences and take actions to accommodate them so that, ideally, each child is provided an optimal learning experience. Effective teachers and classroom managers address the needs of students both in terms of what they teach and how they teach (Save the Children, 2008).

To develop such a learning environment, education officials, school administrators, teachers, students, parents, parent-teacher-teacher associations, and school management committees reflect on the quality indicators. They are related to: i) creation of a relaxed and enjoyable atmosphere ii) retention of control in the classroom iii) presentation of work in a way which interests and motivates students iv) providing conditions so that students understand the work v) making clear what students are to do and achieve vi) judging what can be expected of a student vii) helping students with difficulties viii) encouraging students to raise expectations of themselves x) developing personal and respectful relationships with students (Save the Children, 2008).

\section{Linking behaviour and learning outcomes}

Brown \& McIntyre (1993) state how a teacher perceives behavior management depends on how he sees his job as a teacher and to what extent he believes that all children can learn. Learning outcomes and behaviour are aspects of education that are influenced by teaching quality. A teacher controls many factors that influence students' motivation, achievement, and behaviour. Factors such as a classrooms' physical environment, a child's level of emotional comfort and the quality of communication between teacher and students are important factors that enable or disable optimal learning of individual children.

\section{Equal opportunity and inclusion}

Individuals' needs and difficulties can vary over time and in different settings. Thus, schools and teachers should avoid 'labelling' children and young people. All children must have full access to the mainstream curriculum and classroom activities, providing opportunities for cooperative learning that respects and uses difference and diversity amongst learners. Policy, planning and action in behaviour management should be anti-discriminatory and conform to the principles of equal rights and opportunity (Save the Children, 2008).

\section{Respect for all}

All persons involved in difficulties around behaviour have a right to have their views and feelings taken into account at all times. Policy and practice should actively promote mutual respect for schools, parents, teachers and children without prejudice (Save the Children, 2008).

\section{Positive approaches to behaviour}

In all circumstances, positive approaches to behaviour issues must be used while making an effort to understand the root causes for a specific behaviour from different perspectives. Interventions in response to unwanted behaviour should be the least intrusive. The 'behavioural environment' should be evaluated at the starting point of all interventions and work to improve the 'behavioral environment' should always be accorded high priority (Save the Children, 2008). 


\section{Managing classrooms for better teaching and learning}

The seating arrangement in a classroom can enable or disable interaction and impact student behaviour and attitudes. Thus, it is essential to decide who will sit where and during which activity, based on the teachers' knowledge of their students (UNESCO, 2006). What the teachers do in the class, their values, personality, conduct in class, personality, conduct in class, and manner of handling the class all come into play during the lesson. Effective teachers must respect them as learners and people, and demonstrate care and commitment (Hattie, 2003).

\section{Teacher perceptions and expectations}

Apart from imparting knowledge and skills, teachers also help children define their self-image. Children learn whether they are considered essential, or insignificant, bright or slow, liked or disliked from daily interactions with teachers. Teachers transmit these messages by how they speak to children, their facial expressions and gestures, and the amount of time they devote to each learner. Effective teachers recognize that such involvement does not always come easily- it requires a trusting, psychologically comfortable learning environment. A quality essential to a psychologically comfortable classroom environment is mutual respect (UNESCO, 2006).

\section{Positive and diversity responsive learning environments}

Motivation to learn and to behave well is contingent mainly on interest. If a teacher's teaching can harness children's curiosity, he can also elicit a willingness of students to learn and behave. Interest-satisfying teaching motivates children far more effectively than coercing them into tasks they consider irrelevant and uninteresting (Durrant, 2007). It is a whole-school system wide approach, intended to create a social culture and provide intensive behavioral support, both of which are needed for all students to achieve academic and social success. It is preventive rather than reactive (Horner et al., 2009). Schools continually measure students' social behavior, permitting early intervention and supporting different decisions. The program is based on the principles of behavior analysis. Schools that adopt the program are expected to set up a school wide reward system for good behavior, rather than punishment systems for bad behavior (Babadjanova, 2020).

\section{Conclusion}

I conclude from the discussion above that an integrated approach is needed for effective management as the term management gives holistic meaning. Effective classroom management techniques mostly include effective communication, engagement of students in activities, regular use of questions by teachers, use of behavior contracts, teachers acting as models of good behavior, etc. The implication of the documents analyzed so far is that teachers' classroom management efficiency is a significant predictor of students learning and academic performance. Classroom management is an integral part of effective teaching. It helps prevent behaviour problems through improved planning, organizing and managing of classroom activities, better presentation of instructional material, and better teacher-student interaction, aiming to maximize students' involvement and cooperation in learning. Equally important is the modeling and promotion of good behaviour. Values and social skills have to be taught and modeled by teachers.

Student-centered classroom management is essential because it is based on the premise that a willingness to give up some control and let students take some ownership, which requires spirit 
and talent to the side of the students. While reviewing the literature, the information concludes that cooperative discipline and culturally responsive teaching are management approaches that encourage teachers to manage their classrooms collaboratively with their students in a studentcentered way. When students are given responsibilities at the school, feel their opinions are valued and have a sense of belonging, there is a positive effect on student behavior. School administrators need to support student-centered management and provide training and skills to their teachers because teachers and their students will have higher outcomes and success. High levels of stress and low levels of self-efficacy in teachers are associated with increased use of reactive strategies to deal with student misbehaviour. Functional analysis has become the better standard in managing problem behavior because it involves the determination of the outcomes achieved by children through problem responses and the specific focus of intervention. Thus, knowledge of keystone behaviors and experience with strategies for teaching such skills would be highly advantageous to teachers. The proactive nature of keystone strategies provides increased opportunities for teachers to promote social and supportive behavior for the students.

\section{References}

Acharya, K. P. (2016). Fostering critical thinking practices at primary science classrooms in Nepal. Research in Pedagogy, 6(2), 1-7.

Babadjanova, N. (2020). Effective classroom management techniques for curriculum of $21 \mathrm{st}$ century. Science and Education, 1(7).

Bondy, E. \& Ross, D. (2008). The teacher as warm demander. Educational Leadership, 66(1), 54-58.

Brophy, J. (2006). History of research on classroom management. In C. M. Evertson \& C. S. Weinstein (Eds.), Handbook of classroom management. Research, practice, and contemporary issues (pp.17-43). Malwah, NJ: Lawrence Erlbaum Associates.

Brophy, J. E. (1988). Research linking teacher behavior to student achievement: Potential implications for instruction of Chapter 1 students. Educational Psychologist, 23, 235286.

Brown, S. \& McIntyre, D.I. (1993). Making sense of teaching. Buckingham: Open University Press.

Chaw, L. Y., \& Tang, C. M. (2018). What makes learning management systems effective for learning?. Journal of Educational Technology Systems, 47(2), 152-169.

Denscombe, M. (1998). The good research guide for small-scale social research projects. Open University Press: Buckingham.

Dignath, C., Buettner, G. \& Langfeldt, H. (2008). How can primary school students learn selfregulated learning strategies most effectively? A meta-analysis on self-regulation training programmes. Educational Research Review, 3, 101-129.

Dollard, N., Christensen, L., \& Colucci, K. (1996). Constructive classroom management. Focus on Exceptional Children, 29, 1-12.

Durlak, J. A., Weissberg, R. P., Dymnicki, A. B., Taylor, R. D., \& Schellinger, K. B. (2011). The impact of enhancing students' social and emotional learning: a meta-analysis of schoolbased universal interventions. Child Development, 82, 405-432. 
Durrant, J. (2007). Positive discipline: What it is and how to do it. Bangkok: Save the Children Sweden.

Evertson, C. M. \& Weinstein, C. S. (Eds.) (2006). Handbook of classroom management. Research, practice, and contemporary issues. Mahwah, NJ: Laurence Erlbaum Associates, Inc.

French, R., Imms, W., \& Mahat, M. (2020). Case studies on the transition from traditional classrooms to innovative learning environments: Emerging strategies for success. Improving Schools, 23(2), 175-189.

Gettinger, M. (1988). Methods of proactive classroom management. The School Psychology Review, 17(2), 227-242.

Hall, P. \& Hall, N. (2003). Educating oppositional and defiant children. Alexandria, VA: Association for Supervision and Curriculum Development.

Hattie, J. (2003). Teachers make a difference. What is the research evidence? International Journal of Educational Research, 37, 449-481

Hattie, J. (2009). Visible learning: A synthesis of over 800 meta-analyses relating to achievement. London: Rutledge.

Horner, R. H., Sugai, G., Smolkowski, K., Eber, L., Nakasato, J., Todd, A. W. \& Esperanza, J. (2009). A randomized, wait-list controlled effectiveness trial assessing schoolwide positive behavior support in elementary schools. Journal of Positive Behavior Interventions, 11, 133-144.

Infantino, J. \& Little, E. (2005). Students' perceptions of classroom behaviour problems and the effectiveness of different disciplinary methods. Educational Psychology, 25(5), 491-508.

Johnson, M. (1980). Effective teaching as perceived by teachers and principals in selected Indiana school corporations. Retrieved fromwww.bsu.edu/libraries/virtualpress/ student/dissertations/author_list.asp

Jones, V.F. \& Jones, L. S. (2012). Comprehensive classroom management, creating communities of support andsolving problems (Eds.). Upper Saddle River, NJ: Pearson.

Kagan, S. (2005). Structureel coöperatief leren [Structural cooperative learning]. Vlissingen, the Netherlands: Bazalt.

Kebritchi, M., Lipschuetz, A., \& Santiague, L. (2017). Issues and challenges for teaching successful online courses in higher education: A literature review. Journal of Educational Technology Systems, 46(1), 4-29.

Kern, L., \& Clemens, N. H. (2007). Antecedent strategies to promote appropriate classroom behavior. Psychology in the Schools. Special Issue: The Practitioner's Edition on Promoting Behavioral Competence, 44(1), 65-75.

Kolawole, C.O. (2004). Questioning Strategies in ESL Classroom: An Observation. Journal of the Institute of Education, LASU 2(2).

Kothari, C. R. (2004). Research methodology: Methods and technique (Eds.). New Delhi: New Age International (P) Ltd.

Kyriacou, C.O. (2004). Effective Teaching in Schools. United Kingdom: Stanley Thorues Publishers Ltd.

Lewis, R., Romi, S., Katz, Y. J. \& Qui, X. (2008). Students' reaction to classroom discipline in Australia, Israel, and China. Teaching and Teacher Education, 24(3), 715-724. 
Lewis, T. J. \& Sugai, G. (1999). Effective behavior support: A systems approach to proactive school wide management. Focus on Exceptional Children, 31, 1-24.

Maag, J. W. (2001). Rewarded by punishment: Reflections on the disuse of positive reinforcement in schools. Exceptional Children, 67(2), 173-186.

Malikow, M. (2006). Effective teacher study. National Forum of Education Journal-Electronics, 16(3E), 2005-2006.

Marzano, R. J. (2003). What works in schools. Translating research into action. Alexandria, VA: Association for Supervision and Curriculum Development (ASCD).

Merrett, F. \& Wheldall, K. (1993). How do teachers learn to manage classroom behaviour? A study of teachers' opinions about their initial training with special reference to classroom behaviour management. Educational Studies, 19(1), 91-106. 57

Muijs, D. (2001). Effective mathematics teaching: Year 2 of a research project. Retrieved from:http://highreliability.co.uk/Files/Downloads/Effectiveness/DM2002a.pdf

Oliver, R. M., Wehby, J. H. \& Reschly, D. J. (2011). Teacher classroom management practices: effects on disruptive or aggressive student behavior. Campbell Systematic Reviews, 4, 1-55.

Ostorga, A. N. (2003). The role of values in the development of dispositions. Paper presented at the Second Annual Symposium on Educator Dispositions, 20-21, in Richmond, Kentucky, USA.

Oyira, E. (2006). Effects of classroom learning environment of secondary school students' attitude towards schooling. Journal of Research in Education 5 (4).

Peters, J. H. (2012). Are they ready? Final year pre-service teachers' learning about managing student behaviour. Australian Journal of Teacher Education, 37, 18-42.

Sadler-Smith, E. (1996). Learning styles: a holistic approach. Journal of European Industrial Training, 20(7), [1996] 29-36.

Sanford, J., Emmer, E. T. \& Clements, B. (1983). Improving classroom management. Educational Leadership, 41, 54-60. Goodteacher.htm

Save the Children (2008). Effective Teaching and Classroom Management: One and the same pedagogical approach. Sweden: Author.

Schussler, D. L., Poole, I. R., Whitlock, T. W. \& Evertson, C. M. (2007). Layers and links: Learning to juggle 'one more thing' in the classroom. Teaching and Teacher Education, $23,572-585$.

Shook, A. C. (2012). A study of preservice educators' dispositions to change behavior management strategies. Preventing School Failure: Alternative Education for Children and Youth, 56, 129136.

Smart, J. B., \& Brent, I. L. (2010). A grounded theory of behavior management strategy selection, implementation, and perceived effectiveness reported by first-year elementary teachers. Elementary School Journal, 110, 567-584.

UNESCO (2006). Positive discipline in the inclusive, learning-friendly classroom. Bangkok: Author.

Weinstein, C., Curran, M. \& Tomlinson-Clarke, S. (2003). Culturally responsive classroom management: awareness into action. Theory into Practice, 42 (4), 269-276.

Witcher, A.E., Onwuegbuzie, A. J. \& Minor, L.C. (2001) Characteristics of effective teachers: Perceptions of pre-service teachers. Research in the Schools, 8(2), 2001, 45-57. 